\title{
Langkawi on 'Copenhagen Wheels': exploring eco-conscious urban strategies for island development via cycling technology
}

\author{
R. A. Rahman \& N. R. N. Roslan \\ Centre of Studies for Architecture, Universiti Teknologi MARA, Malaysia
}

\begin{abstract}
This paper addresses the topic of 'urban strategies'. The context is the development on Langkawi, an island destination in Malaysia. The Langkawi Development Authority (LADA) has established a framework for how the island will be developed in the LADA Tourism Blueprint 2011-2015. Eco-tourism is a targeted core business. Much of Langkawi will be conserved as the natural rainforest, limiting the built-up areas to approximately $30 \%$ of the island. Despite the strong implication upon the island's urbanisation, there have not been any specific ecologically conscious urban development strategies within the existing Blueprint. This paper proposes that such strategies need to fulfil both the demand of the expanding tourism industry as well as the need to safeguard the natural ecology of the island. Promoting bicycles as a primary transportation option will serve both. Unlike the normal bicycle, this project looks at integrating the 'Copenhagen Wheel' version. The 'Copenhagen Wheel' turns ordinary bicycles into electric ones via a sensor-type hub that will collect environmental quality data, road conditions and congestion as the bicycle traverses an area. The case study is set for a land parcel in the vicinity of the ferry terminal and the LADA Headquarters. The architectural focus will transform this site into a cyclists' haven and environmental monitoring centre by integrating the 'Copenhagen Wheel' technology into the development model. This is interconnected with the greater framework of enlarging the tourism package for Langkawi whilst sustaining the island's natural environment. This integrated cycling-based project will offer the insights towards eco-conscious urban strategies in island development.

Keywords: island, eco-tourism, cycling-technology, sustainable, development.
\end{abstract}




\section{Introduction}

Langkawi is an island destination in the northwestern part of Malaysia. The Langkawi Development Authority (LADA) has established a framework for how the island will be developed. This is stipulated in the LADA Tourism Blueprint 2011-2015 [1]. Through the implementation of the Blueprint, it is expected that the growth of the tourism industry on Langkawi will expand from the previous RM1.9 billion in 2010 to RM3.8 billion in 2015. The Blueprint identified many barriers that are preventing Langkawi from achieving its full potential as an ecotourism destination. Second on the list of the major barriers is the challenge to preserve the geoparks and natural environments on the island. In response, one of the parameters for future developments includes using only approximately $30 \%$ of the island as built-up areas. The rest of Langkawi will be conserved as the natural rainforest environment. The Blueprint also outlined 14 initiatives to improve the three key themes of tourism products, island infrastructure and tourism enablers. Each of the initiative falls under the purview and responsibility of specific organisation and taskforce. The improvement of Langkawi's connectivity and ground mobility, including providing alternative mode and transportation, is specified under the 14 initiatives.

The Blueprint suggested two potential shuttle routes on the east and west side of Langkawi that will connect major tourist sites as part of the connectivity and ground mobility improvement. This is in addition to enhancing the flight charter services and ferry terminal facilities and surroundings. Beyond this suggestion, nothing else is mentioned in the Blueprint on infrastructural matters. There has not been any focus-area development that investigates specific ecologically conscious strategies in spite of the recommendations outlined in the existing Blueprint. This paper proposes that promoting bicycles as a primary transportation option will contribute towards sustaining the island's natural ecology besides offering an alternative eco-friendly ground transportation mode. This cycling-based design project exploration will also complement an earlier study funded by the LADA Field Study Grant to transform the central business district of Pekan Kuah in Langkawi as a rainforest shopping paradise [2]. These combined strategies are proposed to attract the visitors to stay longer, thus generating more income for Langkawi. International tour groups to Langkawi stay for 4-5 days whilst Malaysian families stay for 3-4 days on average as recorded by the Blueprint. Only the higher-end international visitors stay longer, averaging 8-10 days and this category tends to be guests of exclusive hotelresorts with ample green gardens and natural environment such as the Datai and Four Seasons.

\section{Island tourism and urban sustainability}

Langkawi, like most island nations, lacks renewable natural resources that can support its economic development. It is dependent on the tourism industry that is based on the attraction of sun, sea and sand. However, Langkawi is blessed with a rich biodiversity that is part of million year old rainforest and geological 
features. Eco-tourism is thus a targeted core business. By 2015, Langkawi aims to be the top 10 island and eco-tourism destination in the world (LADA Tourism Blueprint 2011-2015, p.4). Eco-tourism nonetheless is a paradoxical term. Whilst promoting interest in nature and biodiversity among tourists, it is also responsible for nature's degradation when left unchecked and unsupervised. Hall [3] believed that tourism is simultaneously a positive and negative contributor to biodiversity, affecting both the loss of biodiversity and the conservation of nature. Similarly, Hughes [4] considered nature-based tourism and recreation as activities that inflict significant environmental damage and subsequently degrade biodiversity. On one side of the quandary is that the tourists and nature-based recreational participants are a significant threat to nature's biodiversity. On the other, they could be eager learners about the natural environment and its biodiversity.

Cini et al. [5] classified the eco-tourists as holiday-makers who are motivated by the opportunity to experience fusion with nature and other new experiences. This group also exhibits the propensity for conservation and responsible recycling in addition to strong human-nature interactions and tendency towards ecology and nature conservation. They value the intrinsic side of the natural environment. Cameron and Gatewood [6] preferred the term 'experience seekers' as these holiday-visitors seek the natural and un-fabricated destinations that are often enriched by indigenous cultures and eco-experiences. They most likely look for alternative forms of holiday habitation to the standard offerings. It is not a surprise that tourism dependent nations such as Costa Rica and Kenya place a great importance on the idea and brand as green destinations. Even though ecotourism and green destination brands reinforce each other mutually, the terms eco-destinations and green destination brands are not synonymous [7]. A destination might be perceived as having a green brand even though it does not feature or promote eco-tourist attractions or resorts. Alternatively, a destination might receive a large influx of eco-tourists who represent a large slice of its tourism market, but these tourists do not necessarily perceive the destination as a green brand.

An expanding tourism industry also has a strong implication upon an island's urbanisation. It is inadvertent that the natural environment will be destroyed in the process. Although there have been many campaigns about developing ecofriendly cities, the truly 'sustainable' cities would need to simultaneously generate nature and communities besides increasing the life support system to a state long prior to its pre-industrial conditions [8]. This is termed as the 'sustainability standard'. Only through this approach will it be possible to rectify the social, physical and ecological liabilities associated with development. Birkeland [8] does not believe that nature in 'natural' areas can be increased or improved upon. The reason is that such nature "represents the cumulative wisdom of billions of years of evolutionary design." It is therefore incumbent to correct the social or ecological deficiencies caused by past approaches in urban design and development. Renewable resources, the ecological base and 'ecoservices' need to be increased in absolute terms. Eco-services are defined as the natural systems, consisting of elements and forces that constitute the life support 
system. This offers myriad environmental benefits, such as clean air, energy, water, soil and pollination. The proactive approach is to expand future social options by making everyone better off whilst increasing the urban life support system beyond pre-settlement conditions by designing for nature as well as 'with' and/or 'like' nature [8].

Weston and Mota [9] believed in low carbon approaches to tourism. They recommended cycle and walking tourism specifically. Bicycle tourism involves trips away from an individual's home region. Active or passive participation in cycling are considered the main purpose for that trip. This comprises persons who travel for the purpose of engaging in competitive cycling. Persons who travel specifically to observe cycling events are also included in this definition. They encompass both same-day excursionists and overnight visitors [10]. Forsyth and Krizek [11] called for urban designers to design with the different categories of cyclist in mind. This needs to extend into the quality of cycling experiences instead of the current almost exclusive focus on functional issues such as safety and on cycling facilities and networks. A typical cyclist moves around at a more leisurely speed than motor-vehicles, although the skilled and fit riders can go relatively fast (exceeding $30 \mathrm{~km}$ per hour). The independent cycling tourists are well suited for natural environments due to their mobile nature and self-propelled mode of transport. However, this nature experience needs to be supported and facilitated by quality way-finding aids and attributes of cycling routes including surface quality, terrain, safety, and supporting infrastructure (such as rest areas and access to drinking water) to determine the cycle tourists' overall trip satisfaction [12].

The benefits of immersing in nature are well-acknowledged including from the psychological aspects of enhanced kindness and sympathy toward others. This forms part of human's innate affinity with nature. Zhang et al. [13] reported on the empirical evidence that link greater prosociality to having a personal connection with nature and with exposure to natural environments relative to urban settings. Beyond mere exposure to nature, subjective experiences of beauty in nature are specifically linked to prosocial behavior. Awe-related experiences of nature may be strong predictors of prosociality. Prosocial aspirations include inner yearnings such as "To have deep enduring relationships" and "To work toward the betterment of society". Based on a review of the 'TripAdvisor Langkawi Forum' [14], there are tourists who are interested in cycling there. A search query on 'bicycles' gave seven pages of results. Questions about bicycle shops, cycling facilities, rental rates and feasibility of using bicycles to move around the island have been posed on the Forum since 2005. Although the recorded number of enquiries was very small previously, the figure is increasing. From the feedbacks on the Forum, several hotels offer such cycling facilities to their guests. Perhaps due to a short period of stay, the tourists opt to cycle around the hotel trails more than the open roadsides. Among the main grievances about cycling on Langkawi is the hot and humid weather although a seasoned cyclist will know that the situation will be comfortable once the speed reaches $12 \mathrm{~km}$ per hour as the rider would have generated his/her own wind. Riding under huge rainforest canopies will also 
make a lot of difference for both urban and country-side cycling. Currently, there are cycling nature tours being offered to tourists. Dev's Adventure Tour operates cycling trips that are accompanied by trained naturalists who could explain in great length about the flora and fauna besides the local cultural aspects (Fig. 1) [15]. Architectural and urban design approaches that integrate nature immersion as part of the everyday experience for both locals and tourists may well offer the prosocial propensity that is needed within modern society in relation to environmental protection.

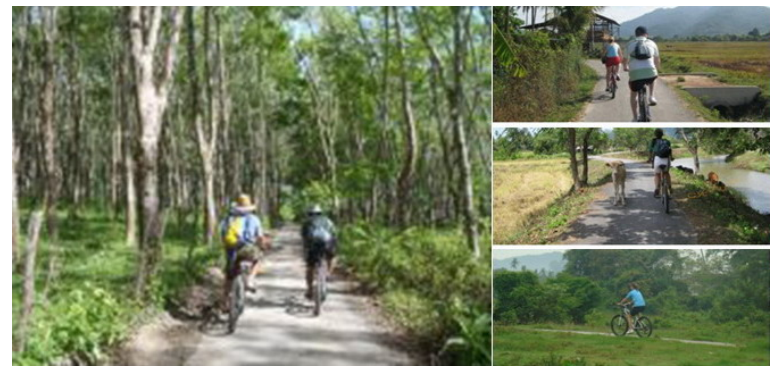

Figure 1: Nature cycling trip on Langkawi.

\section{Design research methodology}

This is a design-based research. The case study is set for a selected land parcel with rich natural green features located across the street from the LADA Headquarters. The Langkawi ferry terminal is also within the vicinity. A skateboarding court occupies part of the land-parcel although this is under-utilised because there are no immediate residential users nearby. The land parcel of four acres is bordered by the main street on the east and recreational park to the west, extending to the sea-front (Fig. 2). The main vegetations on site are the mature rain-trees (Albizia Saman), and Royal and Foxtail palms. An existing service lane runs along the northern part. The south borders a popular parking area that is also lushly vegetated with mature rain-trees (Fig. 3). Whilst the architectural focus is detailed for this site, the greater framework of the proposed system looks at the macro context of the whole island.

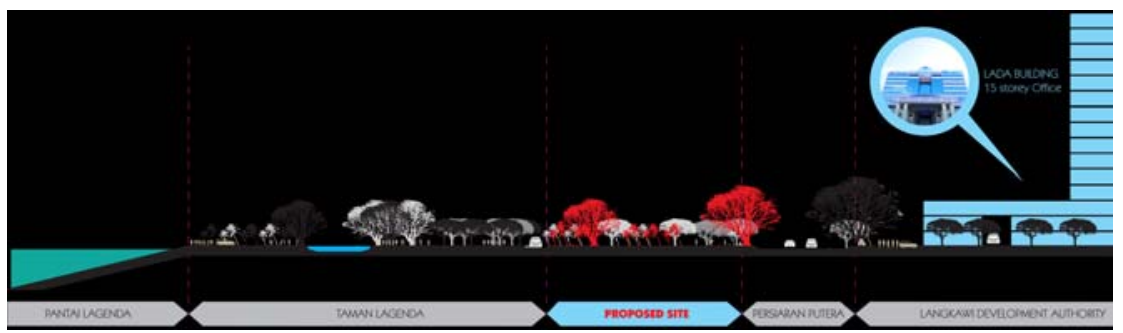

Figure 2: Section through the site. 

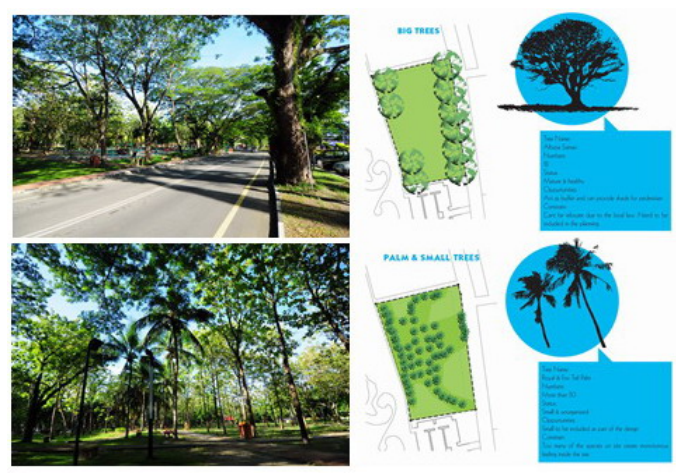

Figure 3: Rain-trees and vegetation around the site.

The design project is a hybrid of a cyclists' haven and environmental monitoring centre. The scheme proposes incorporating the 'Copenhagen Wheel' technology into its framework. The 'Copenhagen Wheel' refers to the MIT's Senseable Lab [16] experimentation launched in 2009 to turn ordinary bicycles into electric ones through the insertion of a packaged hub. The special hub contains a motor, internal hub gear, batteries, torque sensor, GPRS and sensor. The hub will record environmental data such as air (oxygen and $\mathrm{CO}_{2}$ levels), smell, noise, path/road conditions and congestion of the places being traversed. Other aspects relevant to the monitoring such as natural shade level, heat and temperature are also programmable. The data collected from bicycles equipped with the 'Copenhagen Wheel' could be analysed and visualised across the paths that the cyclists travel. An example is of recorded gas pollutant level in an urban trail (Fig. 4) [16]. High-risk areas could easily be deciphered and monitored. Immediate action to resolve any environmental issue can be put in place by the city authorities. The MIT's Senseable Lab project was planned specifically for Copenhagen to enable the city to achieve the carbon neutral capital status by 2025. The commercial version of the 'Copenhagen Wheel' has been advertised beginning the Spring of 2014 and retails at USD699 each. The possibilities of extending the 'Copenhagen Wheel' technology and integrating the approach into Langkawi's eco-conscious urban and architectural development are explored in this paper.

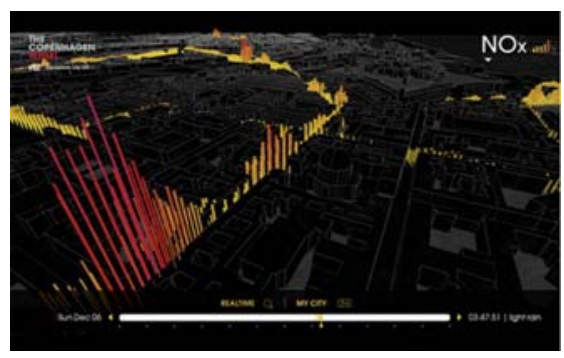

Figure 4: Sample of recorded environmental data. 


\section{Discussion}

This design-research project fits and commemorates the spirit of a major annual international cycling event taking place here - Le Tour de Langkawi. The proposed scheme, named Langkawi Cyclists' Centrifuge, combines four major functions (Fig. 5). The main one is the Environment Monitoring Centre that is combined with a Cycling Exploratorium. This is envisioned as collaborative laboratory that is run by a local university as the local host together with the MIT's Senseable City Lab. The second function is that of a cyclist boutique hotel with a camping-ground for more affordable accommodation option. UiTM is proposed as the local host considering that it has a strong university leadership on environmental research. Besides, UiTM already offers academic programmes on Hotel and Tourism Management and runs a teaching hotel and another training resort near the main campus in Shah Alam. Replicating another hotel on Langkawi with a more focused patronage in mind should not be problematic. The third major function of the Cyclists' Centrifuge is the commercial spaces related to cycling for recreation and sports. This includes a Bike Depot. The fourth and supporting major function is the management office and services.

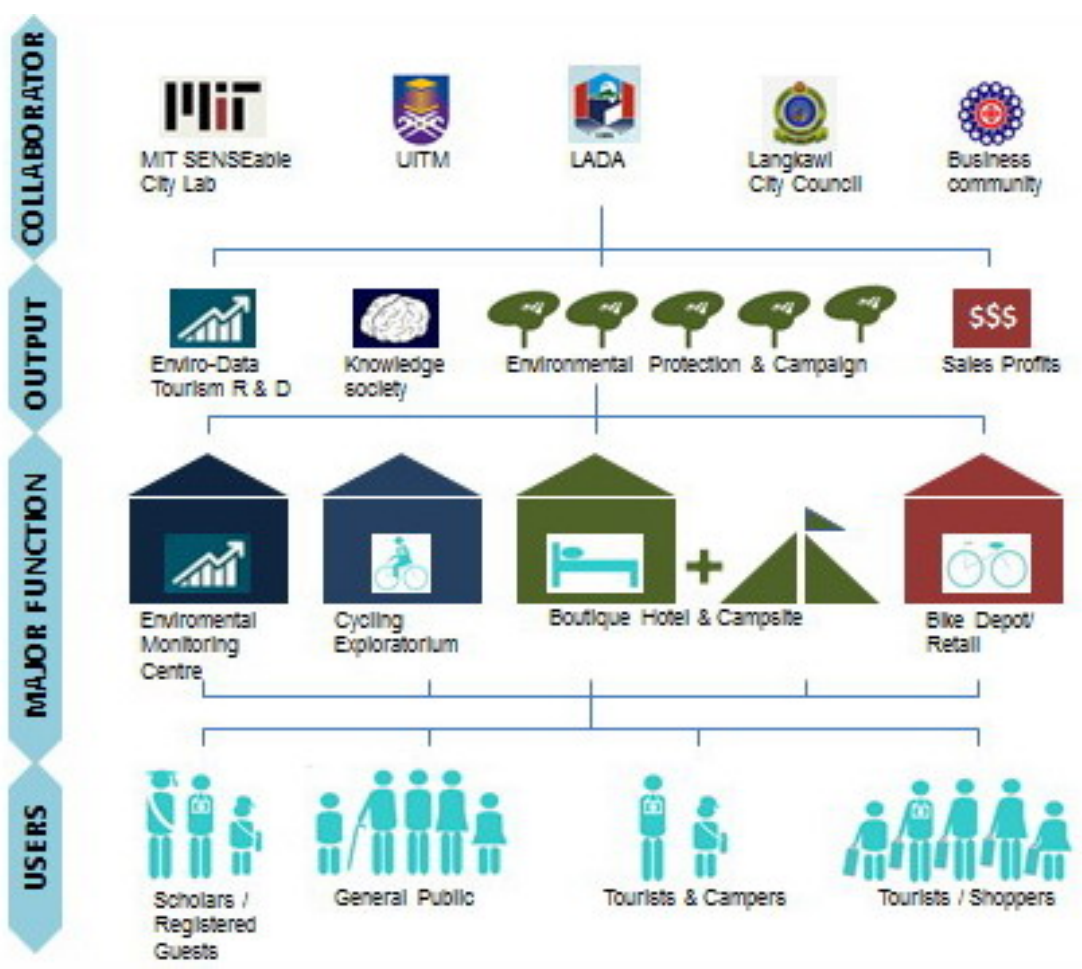

Figure 5: Framework of the Langkawi Cyclists' Centrifuge. 
Overall, the functional programme relates well with UiTM's academic set-up. The university offers courses on Business Management, and Sports Sciences and Recreation. Much R \& D opportunities are foreseeable via this collaboration. The hotel-guests can indicate their interest to contribute to Langkawi's environmental data monitoring by registering as participants upon check-in. As the visitors cycle around the island, they will serve as survey respondents on wheels and as research-helpers simultaneously. This is also a strategy at crowdsourcing from the registered participants. The interested guest-cyclists may rent their bicycles (equipped with the sensor-hub 'Copenhagen Wheel' technology) from the Bike Depot to tour around the island. The hotel accommodation and camp-site for bicycle enthusiasts will serve as a form of environmental campaign. The hotel guests-cyclists will become the actual spokespersons towards conserving Langkawi's biodiversity.

Besides analysing and publicising the data collected from the sensor-hub, the Environment Monitoring Centre-Exploratorium serves an educational intention. Locals and visitors will be made aware of the real-time environmental situation on Langkawi. This may be delivered via huge data screen on-site, or may be accessed on-the-go using smart-phones and other technological gadgets. This aspect is relevant to school-children and students as future inheritors of mothernature. The camping-ground also has them in mind as the students could stay here and be educated about environmental responsibility and prosociality. Besides the main facilities, it is proposed that minor cyclist touch-points be planned at strategic locations on the island. The intermittent touch-points are recommended to serve all categories of tourists and local users should they choose to spend more time at any particular point of interest. These will interweave with existing road network on the island if not with the Blueprint's recommended shuttle routes (Fig. 6).

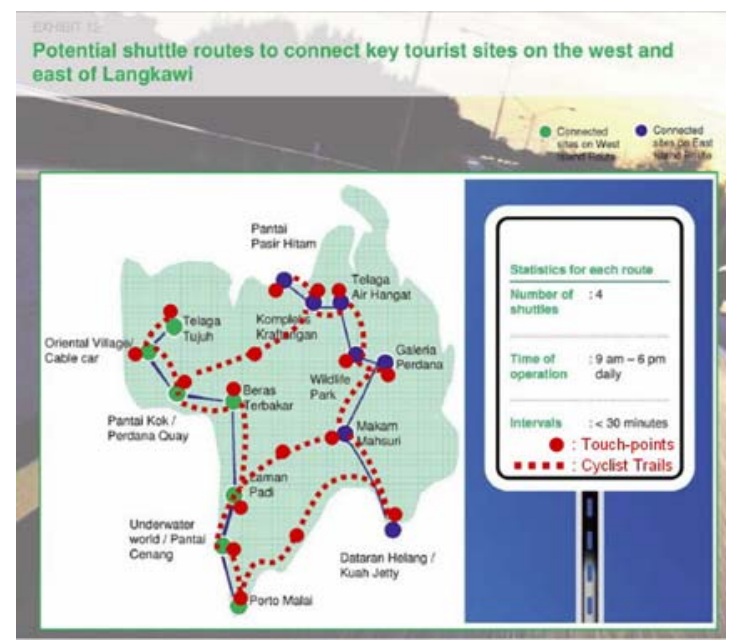

Figure 6: Proposed cycling trails and touch-points interweaving with shuttle network. 
The visitors staying at the Proposed Cyclists' Centrifuge are expected to be bicycle enthusiasts who are environmental-conscientious individuals. This group fits the True-Blue Green category described by Kreidler and Joseph-Mathews [17]. As consumers, this category is 'willing to sacrifice everything in the name of sustainability'. On the other hand, a lean green is willing to participate in sustainable activities as long as there is no additional cost involved. Whilst a surface green understands the concept of sustainability, participating in sustainable activities might be considered too much for him/her. The surface greens may associate themselves with so-called "sustainable" or "green" products but do not do further research on environmental issues or take any extra effort in recycling. The final category of craven green wants to be green and finds the notion of being green attractive. However, their comfort with the way things are or lack of confidence to step outside their usual lifestyle does not change their consumption behavior. In order to modify the lackadaisical attitudes of such groups of consumers on Langkawi, the Proposed Cyclists' Centrifuge is meant to emphasise the connectedness to nature with the hope that proenvironmental actions will be promoted and improved. Mayer et al. [18] made an interesting suggestion in that nature must not only be thought simply as a means to restore depleted attentional capacity and reduce stress. Much more than this, they believed that 'people need to feel a sense of belonging to something larger than themselves'. A sense of belonging or connectedness to the natural world might fulfill this need.

Whilst Langkawi can be proud of its existing natural green settings, it cannot afford to be sitting on its laurel by neglecting or damaging this aspect of its tourism brand. As Insch [7] recommended, a nations' natural assets must be properly managed because these can provide a powerful source of emotional and symbolic value for local and external audiences. It is therefore not enough to simply showcase the natural beauty of the island's landscapes. Rather, Langkawi must promote the philosophies, values and practices of environmental sustainability before it can achieve a positive and sustainable basis of reputational advantage. The Proposed Cyclists' Centrifuge is aimed at illustrating the seriousness of Langkawi to attain such a reputation. At the moment, there are typically two categories of green initiatives on the market [17]. The first one is where green features are integrated into the design characteristics of individual products. Examples include a car designated as having higher miles per gallon or a laundry detergent that is considered as ecofriendly. The second category involves businesses committed to reduction in waste, energy-usage and $\mathrm{CO}_{2}$ emission, and building green.

Nevertheless, the ideal green behaviour that incorporates more holistic sustainable values must form the core principles and values of such a business entity. In this context, LADA as the guardian of Langkawi and associated bodies such as the Langkawi City Council (MPLBP) and business associations need to exhibit such a stance. Having the Cyclists' Centrifuge right in front of the LADA Headquarters speaks volumes of the seriousness towards environmental preservation endeavours. The site is densely vegetated with the local rain-trees and palm trees. The rain-trees provide a well-shaded environment to the site 
besides offering a natural charm and identity for the area. These trees are considered protected species in most parts of Malaysia including here on Langkawi. The design strategy in this project is to build only within the nonvegetated parts of the site and to take a tip-toe approach in terms of placing the building mass onto the land. The rain-trees particularly have the ability to serve as 'flagship' or 'charismatic' species or ecosystems for the more urban parts of Langkawi. The status will depend on the size, height, age and rarity of the trees. Hall et al. [19] suggested that such flagship species can serve as markers in a tourism attraction system whether they grow individually or collectively. Whilst the lone tree will attract a specific attention, trees that grow in groves such as the rain-trees on this project site may acquire a special status and provide the basis of their charisma as the symbols and rallying points on conservation awareness and action. The symbolism is appropriate because being in LADA's vicinity implies that both the Cyclists' Centrifuge and LADA are championing a good cause for Langkawi. This also hints at the blossoming of a new tourist culture.

Whilst many visitors tend to opt for recognised tourists attractions and areas, there are also people who look for an opportunity to experience the everyday life of the real city and destination. According to Maitland [20], some visitors want to experience beyond the enclave of tourist spaces into the more heterogeneous zones where the presence of locals becomes an indicator of authenticity. This group of tourists uses the paths and areas less traveled in a creative way. They are at liberty to construct their personal narratives in relishing the everyday scenes. Compared to spectacular touristic icon bombarding them through media images, the everyday reality of a destination can seem more extraordinary. Being independent on their 'Copenhagen Wheels' whilst weaving through the less beaten tracks of the urban parts and also villages, the tourists might find the authenticity they are seeking for on Langkawi. This too will have the impact of making lesser developed parts of the island more permeable. Currently, the more developed areas are focused on the southern parts of Langkawi around the ferry terminal, Pekan Kuah and the stretch along Chenang Beach. Even though tourists on 'Copenhagen Wheels' have the risk of rebranding the traditional way of life for the locals, it does help with stimulating growth and development to a certain extent. Unlike the typical scenario of having tourists arriving by the bus-loads at a specific spot, the number on bicycles will be more selective and limited. The controlled smaller tourists on wheels will be less intrusive and offers a more down-to-earth social relation necessary to establish rapport with the local community. Most importantly, no $\mathrm{CO}_{2}$ emission is involved in these bicycle excursions.

\section{Conclusion}

The efforts related to cycling for environmental preservation and conservation in other developed places such as Copenhagen, New York and Rotterdam are acknowledged. The awareness for quality environment is catching on with the rest of Malaysia. Shah Alam, as a state capital, has also improved the infrastructural network to include cycling tracks in the city. Kuala Lumpur, as 
the capital city of Malaysia has also embarked on cycling-friendly hours every Sunday. Even the Prime Minister has joined in the cycling-in-the-city campaign. Putrajaya as the new administrative capital of Malaysia has cycling tracks in its masterplan that is slowly being realised. This Proposed Cyclists' Centrifuge is not a matter of jumping onto the bandwagon of sustainability hype. There is an urgent need for this proposal because Langkawi has been listed under the UNESCO Global Geopark Status since 2007 [21]. There is a dire need to rectify its green urban strategies before this status is compromised. Even though the integrated cycling project is still being developed at the conceptual-framework stage, the approach is decisively on green design. "Green design allows cost savings through environmental upgrades to the organization while facilitating a commitment to social responsibility". In concurrence with Kreidler and JosephMathews [17], green design will enable long-term cost savings for Langkawi and LADA as the managing organisation whilst facilitating a collaborative effort in environmental social responsibility. The insights for conserving the bio-diversity of the island are elucidated through the proposed integrated 'Copenhagen Wheels' into the Proposed Cyclists' Centrifuge project inception at the micro and macro scales. The greater framework will also enlarge the tourism package for Langkawi whilst sustaining the island's natural environment. It is not impossible to envision a carbon neutral urbanised island status for Langkawi in the process.

\section{Acknowledgements}

Appreciation is extended to Universiti Teknologi MARA (UiTM) for the logistical and financial support and to the Langkawi Development Authority (LADA) for this research opportunity.

\section{Reference}

[1] Langkawi Development Authority, LADA Tourism Blueprint 2011-2015.

[2] Ab. Rahman, R., Mahdzub, A. F., Yahya, J. \& Zubir, S. S., Re-imagining Pekan Kuah as the Rainforest Shopping Paradise of Langkawi. Lusofona Journal of Architecture and Education, No. 8-9, pp. 731-748, 2013.

[3] Hall, C. M., Tourism and biodiversity: more significant than climate change? Journal of Heritage Tourism, 5:4, pp. 253-266, 2010.

[4] Hughes, M., Blending a heritage of recreation and tourism with conservation of natural heritage: an example from Penguin Island, Western Australia, Journal of Heritage Tourism, 7:1, pp. 1-11, 2012.

[5] Cini, F., Leone, L. \& Passafaro, F., Promoting Ecotourism among Young People: A Segmentation Strategy, Environment and Behavior, 44(1), pp. 87-106, 2012.

[6] Cameron, C. M. \& Gatewood. J. B., Beyond Sun, Sand and Sea: The Emergent Tourism Programme in the Turks and Caicos Islands, Journal of Heritage Tourism, 3:1, pp. 55-73, 2008. 
[7] Insch, A., Conceptualization and anatomy of green destination brands, International Journal of Culture, Tourism and Hospitality Research, Vol. 5, Issue 3, pp. 282-290, 2011.

[8] Birkeland, J., Design Blindness in Sustainable Development: From Closed to Open Systems Design Thinking, Journal of Urban Design, 17:2, pp. 163-187, 2012.

[9] Weston, R. \& Mota, J. C., Low Carbon Tourism Travel: Cycling, Walking and Trails, Tourism Planning \& Development, 9:1, pp. 1-3, 2012.

[10] Lamont, M., Reinventing the Wheel: A Definitional Discussion of Bicycle Tourism, Journal of Sport \& Tourism, 14:1, pp. 5-23, 2009.

[11] Forsyth, A. \& Krizek, K., Urban Design: Is there a Distinctive View from the Bicycle? Journal of Urban Design, 16:4, pp. 531-549, 2011.

[12] Lamont, M. \& Causley, K., Guiding the Way: Exploring cycle tourists' needs and preferences for cycling route maps and signage, Annals of Leisure Research, 13:3, pp. 497-522, 2010.

[13] Zhang, J. W., Piff, P. K., Iyer, R., Koleva, S. \& Keltner, D., An occasion for unselfing: Beautiful nature leads to prosociality, Journal of Environmental Psychology, 37, pp. 61-72, 2014.

[14] TripAdvisor Langkawi Forum, http://www.tripadvisor.com; retrieved 5 August 2014.

[15] Dev's Adventure Tour, Nature Cycling Tour, http://www.langkawinature.com; retrieved 5 August 2014.

[16] MIT Senseable Lab, Copenhagen Wheel, http://senseable.mit.edu/ copenhagenwheel/wheel.html; retrieved 7 May 2014.

[17] Kreidler, N. B. \& Joseph-Mathews, S., How green should you go? Understanding the role of green atmospherics in service environment evaluations, International Journal of Culture, Tourism and Hospitality Research, Vol.3, Issue 3, pp. 228-245, 2009.

[18] Mayer, F. S., Frantz, C. M., Bruehlman-Senecal, E. \& Dolliver, K., Why Is Nature Beneficial? The Role of Connectedness to Nature, Environment and Behavior, Volume 41, Number 5, September 2009, pp. 607-643, 2009.

[19] Hall, C. M., James, M. \& Baird, T., Forests and trees as charismatic megaflora: implications for heritage tourism and conservation, Journal of Heritage Tourism, 6:4, pp. 309-323, 2011.

[20] Maitland, R., Everyday life as a creative experience in cities, International Journal of Culture, Tourism and Hospitality Research, Vol. 4, Issue 3, pp. 176-185, 2010.

[21] UNESCO, Langkawi Geopark (Malaysia), Earth Sciences for Society, http://www.unesco.org/new/en/natural-sciences/environment/earthsciences/global-geoparks/members/malaysia/langkawi-geopark/; retrieved 8 August 2014. 